\title{
Desdobramentos e possibilidades do estágio curricular supervisionado na formação inicial de docentes de educação física
}

Desdoblamientos y posibilidades de la práctica docente supervisada en la formación inicial de docentes de educación física

Developments and possibilities of supervised curricular internship for the initial training of physical education teachers

\section{Volumen 21, Número 2 \\ Mayo - Agosto \\ pp. 1-29}

Arestides Pereira da Silva Júnior

Camila Rinaldi Bisconsini

Patric Paludett Flores

Ana Luiza Barbosa Anversa

Adelar Aparecido Sampaio

Amauri Aparecido Bássoli de Oliveira

\section{Citar este documento según modelo APA}

Silva Júnior, Arestides Pereira da., Bisconsini, Camila Rinaldi., Flores, Patric Paludett., Anversa, Ana Luiza Barbosa., Sampaio, Adelar Aparecido., e Oliveira, Amauri Aparecido Bássoli de. (2021). Desdobramentos e possibilidades do estágio curricular supervisionado na formação inicial de docentes de educação física. Revista Actualidades Investigativas en Educación, 21(2), 1-29. Doi. 10.15517/aie.v21i2.46775 


\title{
Desdobramentos e possibilidades do estágio curricular supervisionado na formação inicial de docentes de educação física
} Desdoblamientos y posibilidades de la práctica docente supervisada en la formación inicial de docentes de educación física

Developments and possibilities of supervised curricular internship for the initial training of physical education teachers

\author{
Arestides Pereira da Silva Júnior ${ }^{1}$ \\ Camila Rinaldi Bisconsini² \\ Patric Paludett Flores ${ }^{3}$ \\ Ana Luiza Barbosa Anversa ${ }^{4}$ \\ Adelar Aparecido Sampaio ${ }^{5}$ \\ Amauri Aparecido Bássoli de Oliveira ${ }^{6}$
}

Resumo: A compreensão dos fenômenos educacionais, a partir da perspectiva dos atores envolvidos vem se mostrando como forma eficaz na qualificação das ações formativas. Dessa forma, a pesquisa objetivou discutir os desdobramentos e as possibilidades do estágio curricular supervisionado na formação inicial de docentes de Educação Física a partir do diálogo de agentes envolvidos com esse componente curricular. Caracterizou-se como exploratória com enfoque qualitativo, na qual participaram 61 pessoas vinculadas à realização do estágio curricular supervisionado do curso de Educação Física Licenciatura da Universidade Estadual de Maringá, Paraná, Brasil. A coleta de dados ocorreu por meio da técnica de grupo focal e de entrevista semiestruturada no ano de 2016 . Foi empregada a análise de conteúdo com a utilização do software NVivo 10. Os resultados evidenciam a relevância do estágio curricular supervisionado na Educação Física, repercutindo em desdobramentos e possibilidades tanto na formação inicial do acadêmico quanto na troca de experiências e formação continuada com os docentes da escola, destacando os conhecimentos da realidade escolar, a construção da identidade docente, a ampliação dos conhecimentos da universidade na escola, a identificação com a etapa de ensino de atuação, o primeiro contato com a escola, as trocas de experiências e formação continuada. Conclui-se que os agentes reconhecem os reflexos do estágio no processo de formação inicial e continuada de docentes de Educação Física, oportunizando inúmeros desdobramentos e possibilidades para a prática pedagógica na área. A pesquisa limitou-se à análise de um contexto específico, mas se reconhece com potencial para aplicação em outras realidades.

Palavras-chave: estágio, educação física, formação profissional, docência.

\footnotetext{
${ }^{1}$ Docente da Universidade Estadual do Oeste do Paraná, Paraná, Brasil. Dirección electrónica: arestidesjunior2000@yahoo.com.br ORCID: https://orcid.org/0000-0003-0647-1930

2 Docente da Universidade Estadual de Londrina, Paraná, Brasil. Dirección electrónica: camibisconsini@gmail.com ORCID: https://orcid.org/0000-0002-1239-118X

${ }^{3}$ Docente da Universidade Estadual do Norte do Paraná, Paraná, Brasil. Dirección electrónica: patricpflores@gmail.com ORCID: https://orcid.org/0000-0003-4865-7661

4 Docente da Universidade Estadual de Maringá, Paraná, Brasil. Dirección electrónica: ana.beah@gmail.com ORCID: https://orcid.org/0000-0003-4363-3433

${ }^{5}$ Docente da Universidade Estadual do Oeste do Paraná, Paraná, Brasil. Dirección electrónica: adelarsampaio@hotmail.com ORCID: https://orcid.org/0000-0003-4386-1364

6 Docente voluntário da Universidade Estadual de Maringá, Paraná, Brasil e da Universidad Católica del Maule, Maule, Chile. Dirección electrónica: amauribassoli@gmail.com ORCID: https://orcid.org/0000-0002-2566-1476
}

Artículo recibido: 18 de noviembre, 2020

Enviado a corrección: 24 de febrero, 2021

Aprobado: 19 de abril, 2021

Los contenidos de este artículo están bajo una licencia Creative Commons 
Resumen: La comprensión de los fenómenos educativos, desde la perspectiva de las personas involucradas, ha demostrado ser una forma efectiva de calificar las acciones formativas. Así, la investigación tuvo como objetivo discutir los desdoblamientos y posibilidades de la Práctica docente Supervisada en la formación inicial de docentes de Educación Física, a partir del diálogo de las personas participantes involucradas con este componente curricular. La investigación se caracterizó como exploratoria con un enfoque cualitativo, en el que participaron 61 personas vinculadas con la realización de la Práctica Docente del curso de Licenciatura en Educación Física de la Universidade Estadual de Maringá, Paraná, Brasil. La recopilación de datos se realizó por medio de la técnica de grupo focal y de entrevistas semiestructuradas en el año 2016. El análisis de contenido de los datos fue realizado con el software Nvivo 10. Los resultados muestran la relevancia de la Práctica Docente Supervisada en Educación Física, lo que se refleja en los desdoblamientos y posibilidades observadas tanto en la formación inicial de la persona académica como en el intercambio de experiencias y educación continua con docentes de la escuela. Entre los desdoblamientos y posibilidades encontradas se destacan el conocimiento de la realidad escolar, la construcción de la identidad docente, la ampliación de los conocimientos de la universidad en la escuela, la identificación con el grado de enseñanza de la práctica, el primer contacto con la escuela, el intercambio de experiencias y la educación continua. Se concluye que las personas participantes reconocen los reflejos de la práctica docente supervisada en el proceso de formación inicial y continua de docentes de Educación Física, lo cual promueve numerosos desdoblamientos y posibilidades para la práctica pedagógica en el área. La investigación se limitó al análisis de un contexto específico, pero se reconoce que existe potencial para su replicación en otras realidades.

Palabras clave: práctica docente, educación física, formación profesional, docencia.

\begin{abstract}
The understanding of educational phenomena, from the perspective of the actors directly involved, has been shown to be an effective way of qualifying training actions. Thus, the research aimed to discuss the developments and the possibilities of the supervised curricular internship in the initial training of Physical Education teachers based on the dialogue of agents involved with this curricular component. The research design is exploratory and qualitative, and had the participation of 61 people linked to the supervised curricular internship of the Physical Education Degree course of the Universidade Estadual de Maringá, Paraná, Brazil. Data collection occurred in 2016 using the focus group technique and semi-structured interview. Content analysis was used using the NVivo 10 software. The results show the relevance of the supervised curricular internship in Physical Education, with repercussions in developments and possibilities both in the initial academic training and in the exchange of experiences and continued training with the school's teachers, highlighting the knowledge of the school reality, the construction of the teaching identity, the expansion of the university's knowledge in the school, the identification with the stage acting teaching, first contact with the school, exchanging experiences, and continuing education. The conclusion is that the agents recognize the reflexes of the internship in the process of initial and continuous training of Physical Education teachers, enabling countless developments and possibilities for the pedagogical practice in the area. Although the research was limited to analyzing a specific context, it recognizes the potential for its replication in other realities.
\end{abstract}

Keywords: internship, physical education, professional training, teaching.

\title{
1. Introdução
}

Nas últimas décadas notam-se destaques em discursos científicos, acadêmicos e políticos sobre a necessidade de se pensar os componentes curriculares dos cursos de formação inicial docente, incluindo a Educação Física, que consolidam a articulação entre teoria e prática a partir do campo profissional. Dentre estes componentes, constata-se em produções científicas internacionais (Chepyator-Thomson e Liu, 2003; Hill e Brodin, 2004; Tang, 2004; Nóvoa, 2009; Belton, Woods, Dunning e Meegan, 2010; Dunning, Meegan, Woods e Belton, 2011; Batista, 2014; Queirós, 2015), bem como, em publicações que retratam o cenário brasileiro, foco deste estudo (Farias et al., 2008; Krug e Krug, 2010; Benites, Souza 
Neto, Borges e Cyrino, 2012; Pimenta e Lima, 2012; Zotovici, Melo, Campos e Lara, 2013; Martiny e Gomes-da-Silva, 2014; Iza e Souza Neto, 2015; Silva Júnior, Flores, Bisconsini, Anversa e Oliveira, 2016; Silva Júnior e Oliveira, 2018a; Oliveira, Silva Júnior, Bisconsini e Flores, 2017; Flores et al., 2019), o avanço do estágio curricular supervisionado, tanto como produção do conhecimento quanto como experimentos de vivências de atuação, demonstrando sua grande abrangência de possibilidades no contexto educacional geral e na Educação Física.

Nesse sentido, considerando as ações que emergem do estágio curricular supervisionado durante o percurso da formação inicial docente, a partir da perspectiva de agentes envolvidos com este componente (coordenadores, docentes supervisores e estagiários), é possível apontar algumas características que são levantadas neste cenário: integração entre as disciplinas do curso e os desafios encarados no dia a dia da educação básica; importância das visitas e do acompanhamento dos docentes da universidade (orientadores) junto a escolas campo de estágio; e o entendimento de que o estágio curricular supervisionado contribui para a formação docente, tanto do estagiário quanto de docentes da escola e da universidade (Bisconsini, Flores e Oliveira, 2016).

No entanto, vale destacar o estudo de Bisconsini (2013) que, ao entrevistar os sujeitos participantes do estágio curricular supervisionado em uma universidade pública do estado do Paraná - Brasil, percebe a fragilidade na preparação de futuros docentes para enfrentarem a realidade escolar, sobretudo no que diz respeito a escassez de tempo para os orientadores supervisionarem/acompanharem os estagiários e a carência de suporte no planejamento dos conteúdos a serem ensinados nas regências. Desse modo, evidencia-se a necessidade de encontrar estratégias para minimizar os desafios apontados pelos próprios atores do estágio curricular supervisionado, a fim de contribuir com esse momento de aprendizagem, com as trocas de experiências provocadas pelas relações estabelecidas na rotina da universidade e escola, além da aproximação dessas duas instituições de ensino.

Além disso, Sampaio, Stobaus, Baez e Ahlert (2017) e Salas (2018) ressaltam ser necessário um investimento mútuo de interligação de saberes, que potencialize um ambiente rico em aprendizagens e competências de atuação diante das diversas situações desafiadoras que a profissão docente apresenta. Nesse sentido, otimizar essa etapa da formação inicial pode ser determinante para novos arranjos do processo educativo, além do engajamento do potencial docente na sua futura carreira. 
Oliveira et al. (2017, p. 70) apontam que "o estágio curricular supervisionado deve proporcionar uma relação adequada e verdadeira entre o processo formativo e a realidade escolar", para que seja estruturado o seu direcionamento a partir da complexidade de relações entre universidade e escola, da valorização de todos os integrantes do processo e da dinâmica relacional entre os componentes curriculares da licenciatura em Educação Física. Por conseguinte, para esclarecer as nuances que permeiam os processos do estágio neste cenário, é preciso que os envolvidos sejam, de fato, protagonistas nessa análise a partir da oportunidade de discutir a importância do estágio curricular supervisionado e seus desdobramentos na formação inicial de docentes de Educação Física.

Ao se colocarem como sujeitos ativos do processo, é possível conhecer as reais demandas do contexto escolar e construir uma relação efetiva entre universidade e escola, a fim de contribuir para a formação inicial de docentes, formação continuada dos supervisores e articulação entre universidade e escola por parte dos docentes coordenadores de estágio.

Nota-se que os estudos indicam os olhares para o estágio curricular supervisionado na perspectiva dos estudantes (Flores et al., 2019; Benites et al., 2019; Cristovão e Ayoub, 2019) e dos docentes supervisores (Bisconsini, Teixeira, Anversa e Oliveira, 2019; Silva Júnior, Bisconsini, Flores, Anversa e Oliveira, 2019), mas poucos se voltam para o olhar do coordenador de estágio ou ainda para a articulação dos três olhares sobre esse momento formativo.

Desse modo, a presente pesquisa contribui ao proporcionar essa articulação que se faz de suma importância para a efetividade das ações, uma vez que os múltiplos olhares e suas trocas favorecem a apropriação metódica das informações, geram a compreensão das ações, dão visibilidade à proposta, antecipam dificuldades, destacam experiências e necessidades, além do clima de confiança, expectativa e cooperação ao longo do estágio curricular supervisionado (Silva, 2003; Zabalza, 2014; Silva, Batista e Graça, 2016).

Considerando o exposto, esta pesquisa apresenta a seguinte questão norteadora: como o estágio curricular supervisionado na formação inicial de docentes em Educação Física é identificado pelos atores que o configuram? Para responder tal inquietude, traçou-se como objetivo discutir os desdobramentos e as possibilidades do estágio curricular supervisionado na formação inicial de docentes de Educação Física, a partir do diálogo de agentes envolvidos com esse componente curricular. 


\section{Referencial teórico}

O estágio curricular supervisionado na formação inicial de docentes se configura como um processo fundamental de experimentação da prática pedagógica, que inclui o planejamento, a intervenção e avaliação. Estas ações possibilitam o exercício da atividade docente no campo real de intervenção (a escola) durante o processo formativo, de modo a favorecer a ressignificação e transcendência de aprendizagens pelo acadêmico, o que muito fortemente impactará na sua atuação profissional futura (Pimenta e Lima, 2012). As mesmas autoras reforçam que o estágio envolve o conhecimento que depende de algumas ações, como o estudo, a análise, reflexão, problematização e ideias de soluções para as diversas situações de ensinar e aprender. Por sua vez, tais ações demandam a capacidade de: analisar o cenário escolar e a respectiva comunidade; utilizar e avaliar técnicas, métodos e estratégias de ensino; ler e reconhecer teorias que sustentam as práticas pedagógicas das escolas e que permitem aos docentes compreender as restrições próprias da instituição de ensino e identificar o potencial transformador das práticas docentes.

De acordo com Pimenta e Lima (2012), a prática como imitação de modelos (conhecida também por aprendizagem artesanal) e a prática como instrumentalização técnica são concepções reconhecidas, mas que já não atendem as necessidades de formação. A primeira, por estar ligada a uma perspectiva de atuação docente que não valoriza sua formação intelectual e é limitada a modelos de observação e imitação, sem a realização de uma análise crítica fundamentada. Já a segunda, por vezes, concebe uma didática instrumental de situações práticas de ensino "iguais" que são resolvidas como técnicas.

Como caminho, a prática como aprendizagem da profissão deve considerar o estágio como campo de conhecimento amplo e contínuo. Isso significa, atribuir-lhe um estatuto epistemológico que supere sua tradicional redução de atividade prática instrumental, possibilitando-Ihe uma relação mais congruente entre os saberes teóricos e os saberes das práticas durante todo o percurso da formação docente (Pimenta e Lima, 2012; Cyrino, 2016).

Nesse sentido, Silva Júnior e Oliveira (2018b) ressaltam a importância da articulação entre as instituições parceiras e os agentes envolvidos direta e indiretamente nesse processo para valorizar as relações que se estabelecem nesse contexto e reconhecer o papel de todos os atores num ambiente harmonioso e propício para a formação do futuro docente. Tal ação favorece uma configuração de aproximação entre universidade e escola, uma vez que ambas são instituições indispensáveis nesse momento formativo, ou seja, a escola e os agentes que 
a integram são corresponsáveis pelo processo de formação inicial docente em Educação Física (Bisconsini et al., 2016).

No contexto da Educação Física, especificamente, a realização do estágio curricular supervisionado, além de resguardar os princípios educacionais na formação de docentes, deve reconhecer as características, competências e habilidades peculiares dessa disciplina tendo em vista que a Educação Física apresenta uma identidade peculiar, seja no seu campo epistemológico ou no contexto de atuação (Gomes, Ferreira, Pereira y Batista, 2013).

Diferentemente dos demais componentes curriculares, a disciplina de Educação Física apresenta características que refletem uma dinâmica norteada por elementos que enaltecem a atratividade para a realização das aulas, como a predominância de atividades práticas, a realização da aula em ambiente fora da sala de aula, a manifestação do lúdico, o contato pessoal próximo entre alunos e a sensação de liberdade nas aulas. Por outro lado, essas mesmas características podem deixar as aulas mais desafiadoras para os docentes, tendo em vista que esses aspectos, ao mesmo tempo que retratam situações "favoráveis" para as aulas, também trazem consigo elementos que poderão externar comportamentos, atitudes e situações mais complexas que serão capazes de realçar manifestações negativas de desrespeito, indisciplina, violência, agressividade, bullying, falta de comprometimento, dentre outras (Kravchychyn, Cardoso, Moretti e Oliveira, 2011; Bertini Junior e Tassoni, 2013; Gomes et al., 2013).

Nesse sentido, Oliveira et al. (2017) revelam que a realização do estágio curricular supervisionado em Educação Física deve resguardar as especificidades da área, considerando as limitações e potencialidades, no intuito de promover uma formação apropriada, condizente e aproximada com a realidade do contexto de atuação. Para os mesmos autores, é nesse período da formação inicial que os aspirantes a docentes da área se deparam com os condicionantes que perpassam o processo de ensino e aprendizagem da disciplina, o que pode causar um choque com a realidade e/ou momentos de descobertas de possibilidades de atuação profissional.

Apesar de algumas dificuldades que ainda são notórias na realização do estágio curricular supervisionado na formação de docentes de Educação Física, constata-se que, atualmente, o estágio vem se configurando e se fortalecendo como uma ação pedagógica que busca romper com a dicotomia entre teoria e prática, de forma a possibilitar um processo ampliado e multidisciplinar, no qual todos os sujeitos são coparticipes (Flores et al., 2019). Tal processo não é simples e fácil, pelo contrário, torna-se complexo e desafiador para todos 
envolvidos, no entanto, sabe-se que essa dinâmica se consolida como um dos elementos essenciais na constituição de rabiscos iniciais de uma identidade profissional dos futuros docentes da área. Caso esse processo gere bons frutos, espera-se profissionais ainda mais qualificados atuando nas escolas, o que pode auxiliar na constante busca de um melhor reconhecimento/valorização da área pela sociedade (Oliveira et al., 2017).

Dentre as fragilidades ainda encontradas, pesquisas recentes direcionadas ao estágio curricular supervisionado na Educação Física brasileira revelam alguns desafios a serem superados, como a necessidade de maior cooperação e parceria entre universidade e escola na realização do estágio (Iza e Souza Neto, 2015), a desvalorização dos aspectos pedagógicos quando comparados aos burocráticos e documentais (Oliveira et al., 2017), a carência de relações harmônicas entre agentes envolvidos diretamente com o estágio (Silva Júnior e Oliveira, 2018b), o não reconhecimento dos docentes de Educação Física da escola como integrantes desse momento de formação (Benites, Cyrino e Souza Neto, 2013) e a falta de uma participação mais ativa dos docentes orientadores de estágio da universidade (Aroeira, 2014).

Embora sejam evidenciadas essas fragilidades, é notório perceber o avanço das pesquisas que vem se dedicando a investigar o estágio curricular supervisionado na formação docente em Educação Física e que poderão repercutir em contribuições para a área, de forma a superar as dificuldades ainda encontradas e aproximar o campo teórico de investigação com o campo prático de atuação (Silva Júnior e Oliveira, 2018a).

Também merece destaque mencionar as transformações ocorridas no campo burocrático e legislativo do estágio curricular supervisionado na formação de docentes de Educação Física. Em uma pesquisa realizada por Silva Júnior, Flores, Bisconsini, Anversa y Oliveira. (2016), os autores elencaram os principais avanços ocorridos nas últimas décadas, destacando: a delimitação da área de conhecimento e intervenção da Educação Física para respaldar as habilidades e competências específicas do componente curricular; o aumento da carga horária do estágio curricular supervisionado em prol de um tempo mais longo de vivência e permanência do futuro docente na escola; a alteração do estágio curricular supervisionado de prática como produto final do curso para atividade específica realizada durante a integralização do curso; e distribuição do tempo de realização do estágio de forma mais harmoniosa e equilibrada com as demais atividades do curso. 


\section{Metodologia}

\subsection{Enfoque}

Trata-se de uma pesquisa exploratória com enfoque qualitativo (Bogdan e Biklen, 2013), tendo em vista a busca de esclarecimento e aprofundamento na investigação sobre os desdobramentos e as possibilidades do estágio curricular supervisionado na formação de docentes de Educação Física, a partir de uma ampliada pesquisa de campo com as pessoas que participam efetivamente desse momento da formação.

\subsection{Unidades de análise}

A pesquisa contou com a participação de 61 pessoas vinculadas ao estágio curricular supervisionado de uma instituição de ensino superior do município de Maringá - Paraná Brasil, sendo: 33 alunos estagiários dessa instituição; 23 docentes de Educação Física de escolas públicas da educação básica, denominados de Docentes Supervisores; 5 docentes coordenadores de turma de estágio da instituição de ensino superior. Os critérios de inclusão para participação na pesquisa foram os seguintes: a) Estagiários: estarem matriculados na disciplina de estágio curricular supervisionado; aceitarem participar da pesquisa; b) Docentes Supervisores: pertencerem ao quadro de docentes de Educação Física da rede municipal e/ou estadual de ensino do município de Maringá - Paraná - Brasil; terem recebido acadêmicos da IES investigada para a realização do estágio; aceitarem participar da pesquisa; c) Docentes coordenadores de turma de estágio curricular supervisionado: serem docente responsável por turma de estágio curricular supervisionado; aceitarem participar da pesquisa.

Os relatos dos participantes da pesquisa são apresentados pela sigla correspondente a sua posição laboral e acadêmica (Docente Supervisor - DS; Docente Coordenador de Turma - DCT; Estagiário - E), seguido de numeração progressiva (1, 2, 3, 4, 5...). Todos os participantes foram informados dos objetivos e procedimentos, bem como assinaram o Termo de Consentimento Livre e Esclarecido.

\subsection{Técnicas de coleta de dados}

A coleta de dados foi realizada no ano de 2016 e envolveu a técnica de grupo focal com os docentes supervisores e estagiários, além da entrevista semiestruturada com os docentes coordenadores de turma. Justifica-se a realização de procedimentos de coleta de dados diferenciados (grupo focal e entrevistas), tendo em vista que o quantitativo de docentes coordenadores de turma era insuficiente para a realização de grupo focal. 
Os procedimentos de coleta de dados para o grupo focal seguiram as recomendações de Gatti (2012). Dessa forma, foram formados oito grupos realizados em sessão única, sendo quatro compostos por docentes supervisores e quatro por estagiários. As reuniões de cada grupo tiveram duração aproximada de 100 minutos, sendo gravadas por vídeo e áudio, mediante autorização dos participantes. Para a condução das reuniões do grupo focal participaram um mediador, um relator e um observador, os quais passaram por treinamentos prévios para minimizar as chances de eventuais erros e dinamizar a realização dos procedimentos.

As entrevistas com os docentes coordenadores de turma foram realizadas individualmente (entrevistador e entrevistado) em sala adequada e com a utilização de um gravador portátil, tendo duração aproximada de 30 minutos. Todo o conteúdo das entrevistas foi transcrito e encaminhado por e-mail aos entrevistados para a conferência das informações e autorização, seguindo as recomendações de Duarte (2004) e Negrine (2004).

Tanto para a realização dos grupos focais quanto das entrevistas, no intuito de atingir os objetivos propostos da pesquisa, as interlocuções foram guiadas a partir de um roteiro semiestruturado, contemplando temas e questões definidas (categorias) referentes aos desdobramentos e possibilidades do estágio: a relevância desse componente curricular no processo formativo e no contexto de atuação; a relação entre escola e universidade; a relação teoria e prática; a construção da identidade docente; e as dificuldades existentes no processo.

A pesquisa foi submetida e aprovada pelo Comitê Permanente de Ética em Pesquisa com Seres Humanos - COPEP da Universidade Estadual de Maringá - Paraná - Brasil, conforme Parecer Consubstanciado $\mathrm{n}^{\circ}$ 1.113.894. O procedimento está de acordo com a disposição do Ministério da Saúde, a partir das normas e diretrizes do Conselho Nacional de Saúde que regulamentam a pesquisa em seres humanos (466/2012), de forma a favorecer o respeito e a dignidade humana, além de garantir o desenvolvimento da pesquisa dentro dos princípios éticos.

\subsection{Análise dos dados}

Em relação à análise dos resultados, procedeu-se com a análise de conteúdo (Bardin, 2013), a partir de procedimentos dedutivos (a priori) e indutivos (posteriori) (Queirós e Graça, 2013). Considerando os objetivos propostos e o referencial teórico utilizado, foi elaborada uma matriz analítica com categorias definidas a priori - dedutivas (já mencionadas no tópico anterior). Após a coleta de dados foi realizada a análise indutiva (posteriori), considerando as 
categorias existentes, mas oportunizando novas informações e códigos, configurando as seguintes categorias de análise: conhecimento da realidade escolar; construção da identidade docente; articulação entre os conhecimentos da universidade na escola; identificação com a etapa de atuação; primeiro contato com a escola; e troca de experiências e formação continuada.

De acordo com Bardin (2013, p.15), a análise de conteúdo é entendida "[...] como um conjunto de instrumentos de cunho metodológico em constante aperfeiçoamento, que se aplicam a discursos (conteúdos e continentes) extremamente diversificados", ainda, deve ser realizada de forma contínua e progressiva para atender à três fases: pré-análise, exploração e tratamento, bem como inferência e interpretação dos resultados. Algumas falas dos participantes da pesquisa foram utilizadas e apresentadas na íntegra, no sentido de representar e/ou exemplificar qualitativamente tal resultado da totalidade ou de parte do grupo.

Para auxiliar no processo de análise e interpretação do material coletado, aplicou-se o software de análise qualitativa NVivo 10. De acordo com Benites, Nascimento, Milistetd e Farias (2016), programas computadorizados têm sido empregados com bastante frequência nas pesquisas qualitativas, principalmente por proporcionarem recursos que ajudam a organizar os dados coletados. No entanto, os autores ressaltam que a utilização dessa ferramenta não elimina o papel rigoroso e complexo do pesquisador.

\section{Resultados e discussão}

As diversas e ampliadas possibilidades do estágio curricular supervisionado na formação inicial de docentes de Educação Física são amplamente reconhecidas, como a oportunidade do contato inicial com o contexto escolar e reflexões sobre os condicionantes que estão por trás da profissionalidade docente. Sobretudo na última década, ocorre a divulgação de pesquisas que abordam essa temática em suas diversas vertentes, as quais buscam levantar discussões a partir do olhar dos diferentes agentes que estão envolvidos nesse processo, seja de forma isolada ou articulando as múltiplas interpretações desses sujeitos.

Nesse sentido, sob a ótica do aluno estagiário, identificam-se algumas temáticas como as preocupações pedagógicas que emergem durante essa fase da formação (Farias et al., 2008), as experiências didáticas adquiridas no campo escolar (Moletta et at., 2013; Santos, Souza e Barbosa, 2013; Martiny e Gomes-da-Silva, 2014; Krug, Krug, Marques e Conceição, 2015), e a relevância desse componente curricular dentro da formação docente em Educação 
Física (Krug e Krug, 2010; Souza Neto, Benites, laochite e Borges, 2012; Neira e Ehrenberg, 2013; Flores et al., 2019).

Outro ator que se faz presente nas produções sobre o estágio é o docente da escola (supervisor), o qual relata desde as fragilidades na supervisão do estagiário à ações que se configuram em aprendizagens significativas para a profissão (Benites et al., 2012; Benites et al., 2013).

O estágio curricular supervisionado também é retratado sob a visão dos docentes universitários, os quais reforçam o papel do mesmo frente a formação do futuro docente em Educação Física (Silva, Souza e Checa, 2010), bem como, reconhecem que pode ser um espaço de formação em serviço do docente do ensino superior e da escola (Bisconsini et al., 2016).

Para além dos estudos que destacam as percepções de cada sujeito envolvido no estágio, também se encontram produções que articulam os olhares de mais de um agente, levantando as facilidades e dificuldades que são enfrentadas por cada um (Aroeira, 2014; Iza e Souza Neto, 2015) e/ou reflexões que elucidam as configurações que se estabelecem durante esse processo frente a conexão universidade e escola (Zotovici et al., 2013; Silva Júnior et al., 2019).

Os resultados desta pesquisa corroboram com a literatura supracitada ao reconhecerem as contribuições do estágio curricular supervisionado na Educação Física, principalmente na formação inicial do futuro docente, mas também como modo de formação continuada aos docentes da escola e universidade, uma vez que, fortalece a valorização da formação em contexto real de ensino, propiciando momentos de reflexão e articulação de dispositivos que facilitam a busca por uma educação de qualidade (Chepyator-Thomson e Liu, 2003; Hill e Brodin, 2004; Tang, 2004). Ainda nessa direção, Silva Júnior (2016) e Oliveira et al. (2017) revelam que o estágio curricular supervisionado é uma possibilidade ímpar no processo de formação inicial e continuada do docente de Educação Física, pois proporciona momentos de aprendizado, ensinamento, reflexão, experimentação e avaliação da prática pedagógica no processo formativo da Educação Física.

Nesse sentido, os achados que emergiram da coleta de dados, extraídos dos significados das falas, foram organizados e apresentados na Figura 1, de forma a possibilitar uma visão global das implicações do estágio curricular supervisionado no contexto da formação docente em Educação Física. 
Figura 1

Desdobramentos e possibilidades do estágio na formação de docentes de Educação Física na Universidade Estadual de Maringá (UEM) - Brasil, 2016.

\begin{tabular}{|c|c|c|}
\hline $\begin{array}{c}\text { Conhecimento da } \\
\text { realidade escolar }\end{array}$ & $\begin{array}{c}\text { Construção da identidade } \\
\text { docente }\end{array}$ & $\begin{array}{c}\text { Articulação entre os } \\
\text { conhecimentos da } \\
\text { universidade e escola }\end{array}$ \\
\hline $\begin{array}{c}\text { Identificação com a etapa } \\
\text { de atuação }\end{array}$ & $\begin{array}{c}\text { Primeiro contato } \\
\text { com a escola }\end{array}$ & $\begin{array}{c}\text { Troca de experiências e } \\
\text { formação continuada }\end{array}$ \\
\hline
\end{tabular}

Fonte: Elaboração dos autores, a partir dos resultados das análises, 2016.

O conhecimento da realidade escolar foi um aspecto amplamente evidenciado nos relatos dos participantes da pesquisa (DCT1, DCT4, DS3, DS4, DS5, DS7, DS10, DS14, E9, E16, E20, E23, E31, E33). A fala do DCT1 representa o que outros relatos também expuseram, segundo tal docente, a importância se dá no sentido de "participar de todo o contexto da escola, a dificuldade da falta de material, da falta de estrutura [...] é uma realidade que ele vai ter que enfrentar, durante todo período de trabalho". No mesmo sentido, evidenciam-se algumas falas dos estagiários no grupo focal, como, por exemplo, o E16 ao relatar que "[...] é um verdadeiro choque de realidade, porque, às vezes, quando você entra no curso, você imagina uma coisa, [...] mas quando você vai para dentro da escola, você vê que as coisas mudam muito".

Nessa categoria também foram evidenciadas as possibilidades de conhecimento sobre a escola para além dos problemas relativos ao "choque de realidade", como por exemplo: vivenciar o cotidiano da escola, envolver-se na dinâmica institucional, conhecer os agentes do contexto escolar (direção, equipe pedagógica, funcionários administrativos, zeladoras, merendeiras, etc.), conhecer os alunos, relacionar-se com a comunidade escolar, dentre outros. Nessa conjuntura, tem-se o relato do DS14 que indica que o estágio curricular supervisionado "é a possibilidade de conhecimento amplo da escola, das turmas, das faixas etárias dos alunos, do projeto político pedagógico da escola, da questão do planejamento, das reuniões pedagógicas, dentre outros". Destaca-se também a afirmação do DCT4 que citou "é quando o aluno vê na prática do dia-a-dia como é a rotina da escola, como que funciona a sua estrutura, a organização escolar e como é que aquilo tudo que ele aprendeu durante dois ou três anos de formação no curso de Educação Física".

Queirós (2015) relata, a partir de sua experiência em Portugal, que um dos efeitos do estágio é a oportunidade da imersão frente a cultura escolar em suas diversas facetas, desde 
as suas normas e valores, aos seus hábitos, costumes, práticas que interferem no sentir, pensar e agir daquela comunidade em específico. Nesse sentido, Silva Júnior (2016) reforça que o estágio curricular supervisionado na formação de docentes de Educação Física é a possibilidade de experimentação da prática pedagógica no contexto da aplicação da aula, mesmo com as adversidades existentes, como: a indisciplina de alunos, a precariedade das condições de trabalho (espaço físico e materiais) e os vários problemas sociais (drogas, violência, prostituição, miséria, dentre outros) no seu contexto e entorno.

Além das dificuldades apresentadas, a Educação Física traz em seu histórico pouco reconhecimento, pois ainda é vista de forma negativa e simplista, normalmente restrita aos cuidados com o corpo, associada ao jogo e à recreação, à "prática pela prática", ou sem uma organização e sistematização de conteúdos como as demais disciplinas oferecem, o que dificulta a sua legitimidade pedagógica (Kravchychyn et al., 2011; Bertini Junior e Tassoni, 2013).

A construção da identidade docente e identificação com a profissão também foram aspectos bastante presentes nas falas, principalmente dos docentes coordenadores de turma e supervisores de estágio curricular supervisionado (DCT2, DCT3, DCT4, DS2, DS4, DS5, DS9, DS12, DS13, DS16, DS21, E2, E3, E11, E29). Nos grupos focais, várias falas chamaram a atenção e ampliaram a discussão, como as representadas por DS4 e DS16, respectivamente. "O estágio é uma oportunidade de a pessoa verificar se é aquilo mesmo que ela quer para a carreira profissional, trabalhar com criança (DS4)". "A importância de vivenciar a Educação Física na escola como forma de experimentar se essa é a área que ele deseja atuar (DS16)". O DCT4 afirma que "é o momento de inquietude, então ele deve refletir sobre suas ações e questionar: o que estou apreendendo nesse momento? Como é que uso o que eu aprendi? Quais as dificuldades?"

Por outro lado, alguns docentes supervisores (DS7, DS8, DS15, DS18, DS22, DS33) relataram que embora o estágio curricular supervisionado apresente elementos importantes para a construção da identidade docente, reconhecem que existe um distanciamento entre formação e atuação, como disse o DS7: "eu acho que a realidade da profissão está muito distante da formação, [...] essa dificuldade aconteceu conosco e ainda perdura".

A vivência em contexto real da futura profissão favorece a constituição da identidade docente, uma vez que, segundo Dubar (1999), a experiência na ação remete à compreensão de sentimentos, dificuldades e conflitos que podem refletir ou não no sentimento de pertencimento. Ao estabelecer relações nas vivências de estágio curricular supervisionado, 
estudantes, docentes supervisores e coordenadores de estágio interiorizam saberes, experiências e reflexões úteis para a atividade profissional e assim se projetam enquanto pessoa e profissional, com isso buscam meios de consolidar o ser e estar na profissão a partir de práticas que tragam os objetivos do exercício profissional, sua organização e pertença social, bem como motivações, projetos e competências (Silva, 2003). Vale ressaltar que, esta crença parte da noção de que as aprendizagens profissionais emergem de forma mais significativa quando situadas no ambiente profissional e em colaboração com profissionais experientes (Jones e Straker, 2006).

Desse modo, nota-se que as trocas e experiências na Educação Física carregam algumas características próprias. Por meio de uma revisão sistemática com abrangência internacional, acerca da identidade profissional do docente de Educação Física, Gomes et al. (2013) evidenciaram que, apesar de alguns traços comuns com os demais docentes, a especificidade da disciplina e o seu contexto de atuação desenham uma identidade particular. De fato, tais enlaces que o estágio curricular supervisionado proporciona corroboram para o desenvolvimento da identidade profissional e constituem um elemento decisivo na formação de docentes no sentido de proporcionar a tomada de consciência e a reflexão sobre o modo como os alunos se veem enquanto docentes e o tipo de docentes que aspiram vir a ser (Flores, 2015).

Nesse sentido, também se destacam menções de estagiários que se sentiram inseguros e indecisos sobre a continuidade na profissão docente, como exemplificado pelo E16 ao dizer que "quando você entra no curso, você imagina uma coisa, mas quando você vai para dentro da escola, você vê que as coisas mudam muito, então, acho que é um 'choque de realidade' na escolha da futura profissão, para quem vai seguir a carreira da licenciatura". De acordo com Oliveira et al. (2017), essa fragilidade existente entre a expectativa do processo formativo da universidade e a realidade posta no contexto de atuação da escola ainda é reconhecida como um dos principais problemas durante a imersão do acadêmico no estágio curricular supervisionado no fortalecimento de sua identidade docente.

Docentes e estagiários (E3, E4, E19, E27, E29, DS5, DS10, DS14) também apontaram a articulação entre os conhecimentos da universidade na escola. O E19 afirmou que "é o momento que se coloca em prática a teoria vista até então na faculdade" [...]. "Até no terceiro e quarto ano, a gente vê muita teoria e aplica as práticas para nossa própria turma, então, quando a gente sai e tenta aplicar isso para as crianças, [...] é uma realidade diferente". 
Na mesma linha de raciocínio são mencionadas algumas falas de docentes, por exemplo a afirmação do DS10: "na teoria era uma coisa linda, quando chegou na prática a gente sai frustrado porque não consegue aplicar". Já o DS12 afirmou que:

A experiência com o estágio é o que realmente dará embasamento prático ao estudante, é nesta vivência que o estagiário irá perceber a realidade escolar, tanto nos acertos, quanto na tentativa de resolução de problemas gerados no decorrer da aula, bem como compreender um pouco mais a lógica das questões burocráticas no interior das instituições de ensino.

Segundo Borba e Wittizorecki (2013), a escola é repleta de relações (negociações, acordos e concessões) que influenciam o trabalho docente, tais como situações de imprevisibilidade, ajustes, acontecimentos inusitados, tensões, conflitos, atravessamentos gerenciais e socioculturais. Essas relações são definidas por Ball (1989) na obra " $L a$ micropolitica de la escuela: hacía una teoría de la organización escolar", como a micropolítica escolar, caracterizada por uma complexidade de relações, processos, dinâmicas e interlocuções presentes no contexto escolar.

Desse modo, as relações existentes na escola são restritas a esse espaço educativo e de difícil encenação no processo educativo quando limitadas ao ambiente da universidade. Por isso, o estágio curricular supervisionado se caracteriza como um importante momento de transcendência e de articulação dos conhecimentos apreendidos na universidade e aplicados no cotidiano das escolas.

Além disso, o estágio curricular supervisionado deve ser considerado como campo de conhecimento que possibilite ao estudante a ressignificação de suas práticas pedagógicas, a fim de superar a tradicional redução à prática instrumental. Portanto, faz-se necessário que as disciplinas que compõem os cursos de formação estabeleçam os nexos entre os conteúdos que desenvolvem e a realidade para possibilitar que o ensino ocorra de forma a aproximar universidade e escola (Pimenta e Lima, 2012). Ademais, Neira e Ehrenberg (2013) afirmam que os momentos de relatos de experiência sobre o estágio curricular supervisionado se constituem como oportunidades para socializar e compartilhar vivências pedagógicas que auxiliarão no processo de ensino-aprendizagem do futuro docentes e, consequentemente, na aproximação entre os conteúdos ensinados na escola e universidade.

Nesse direcionamento, uma das fragilidades apresentadas foi a falta de experiência dos docentes da universidade sobre a escola, exemplificada pelo relato do DCT2 ao dizer: "olha, 
é difícil, porque tem professores aqui que nunca trabalharam na escola e estão ministrando aula sobre a escola". Silva Júnior (2016) reforça a importância da vivência, da experiência e do conhecimento sobre a realidade escolar para os docentes que acompanham o estágio, pois facilita sobremaneira a relação existente e a apresentação de possibilidades pedagógicas.

O estágio curricular supervisionado como possibilidade de identificação da etapa de ensino com maior afinidade foi apontado por docentes e estagiários (E2, E4, E11, E15, E20, E28, E31, DCT1, DS6, DS12). De acordo com o E15, "identificar qual faixa etária a gente gosta mais para trabalhar". O E28 disse: "Eu achei que eu iria me dar melhor com o Ensino Fundamental do que com o Ensino Médio e foi totalmente ao contrário, porque eu descobri que eu não gosto de ficar falando muito, mas com criança você precisa falar muito". Na mesma direção, o DCT1 revelou que "depois do acadêmico ter vivenciado o estágio em seus diferentes níveis ele tem condições de reconhecer a afinidade para sua escolha de atuação. Para mim, isso é um indicador de que estágio foi importante na sua opção de trabalho docente com melhor qualidade".

De acordo com Silva Júnior (2016), a vivência do estágio curricular supervisionado nas diferentes etapas da educação básica (educação infantil, anos iniciais e finais do ensino fundamental e ensino médio), amplia as possibilidades de aprendizagem docente no processo formativo, haja vista a oportunidade de conhecer as características dos alunos em questão e os objetivos para cada turma, o que permite analisar se existe maior afinidade com determinada faixa etária para ensinar os conteúdos da Educação Física.

Ainda em relação à identificação da etapa de ensino, é importante considerar a riqueza, grandeza e complexidade da disciplina de Educação Física na educação básica, procurando no estágio curricular supervisionado vivenciar e explorar as unidades temáticas, os objetos de conhecimento e as habilidades, em consonância com a sistematização e organização dessa disciplina nos documentos oficiais, para entender o processo de planejamento, execução e avaliação das práticas pedagógicas nas devidas séries/anos, tanto do Ensino Fundamental quanto do Ensino Médio.

Nesse percurso formativo a relação universidade e escola deve ser fortalecida desde o início do curso de formação. Na legislação brasileira, a partir de 2002, regulamentou-se que os cursos potencializassem essa ação por intermédio das Práticas como Componente Curricular (PCC), ou seja, realizar a simetria invertida, a universidade forma para a escola e a escola forma para a universidade, uma troca continuada de saberes que fortalecem o processo de construção do futuro docente. Desde então, os cursos devem se organizar de modo a 
realizar ações que aproximem o futuro docente desde o seu primeiro ano de graduação com a realidade da escola. Cabe destacar, que as atuais diretrizes curriculares nacionais para a formação inicial de docentes na educação básica estabelecem “400 (quatrocentas) horas para a prática dos componentes curriculares [...] distribuídas ao longo do curso, desde o seu início, segundo o Projeto Pedagógico de Curso da instituição formadora" (Brasil, 2019, p. 5).

Para Bisconsini e Oliveira (2018), a PCC é uma forma de articular os diferentes saberes docentes, pois permite o diálogo entre docentes universitários, licenciandos e docentes que atuam junto aos escolares. Estes agentes mobilizam os diversos saberes ao longo da formação e carreira profissional, com rotas que permitem ressignificá-los nesse processo. Contudo, a contribuição para a aprendizagem docente demanda o estreitamento na relação entre os ensinos básico e superior, especificamente nas licenciaturas. Para os mesmos autores, as referências dos discentes sobre a profissão se multiplicam quando também se diversificam os ambientes e contextos de ensino e aprendizagem, com possível provocação para posturas críticas diante de análises sobre a complexidade do cenário específico da educação básica. A fim de complementar essa ideia, Oliveira et al. (2017) lembram que o estágio curricular supervisionado e a PCC formam um eixo articulador no currículo, por se constituírem como ações permanentes no curso de formação inicial e amarrarem as ações pedagógicas.

No entanto, os resultados da pesquisa evidenciaram ser o estágio o primeiro contato com a escola, sendo este um dos aspectos elencados como importante para alguns estagiários (E1, E10, E13, E29) e docentes supervisores (DS3, DS6 e DS22). Conforme o E1, o estágio curricular supervisionado apresenta a sua importância por ser "o primeiro contato com a escola após dois anos de curso [...] a escola apresenta um universo diferente, a gente não sabe exatamente a rotina que vai ser". No mesmo direcionamento, o E29 afirma que "é o primeiro contato que a gente tem com o nosso futuro ambiente profissional. Ali é onde vai acabar com o medo inicial, [...] começar a vivenciar e colocar os conteúdos que a gente aprendeu na faculdade em forma de prática aplicada".

Ressalta-se que na instituição de ensino superior pesquisada, em especial no curso de licenciatura em Educação Física, o estágio curricular supervisionado acontece a partir da segunda metade do curso, sendo os primeiros anos um momento de construção e aprofundamento do leque de saberes e conhecimentos próprios da profissão docente, que deveriam estar aliados a interlocuções com a prática interventiva por meio da PCC ou outras 
ações formativas nas disciplinas curriculares, conforme já salientado por Bisconsini e Oliveira (2018).

Tais dados, apesar de ilustrarem a relevância do estágio curricular supervisionado, chamam atenção para o desconhecimento desses docentes e estagiários em relação à PCC, que deveria ser o primeiro contato do estudante com a escola na formação inicial (Maffei, 2014; Silva Júnior et al., 2016; Bisconsini e Oliveira, 2018). Ainda, os mesmos resultados também podem indicar que a prática como componente curricular não integra o currículo efetivo do curso, o que pode ser considerada uma fragilidade passível de implicar sobre a configuração do estágio curricular supervisionado, tendo em vista que o estágio deve suprir demandas anteriores destinadas às práticas como componentes curriculares (Batista, 2014).

Vale reforçar o fato de que, apesar de a PCC ser prevista no curso investigado e integrar as diretrizes curriculares nacionais para a formação de docentes, esta prática não está presente na rotina do curso, o que pode ser ratificado pelos alunos que afirmam ser o estágio o primeiro contato com a escola durante a formação inicial. Isso pode se dar, entre outros motivos, pela própria imprecisão da PCC nos Projetos Pedagógicos correspondentes e na representação do estágio curricular pelo corpo docente, que pode entendê-lo como suficiente para aproximar os estudantes do futuro espaço social de intervenção.

Para haver mudanças neste cenário específico, é indispensável a ressignificação sobre as responsabilidades de cada um dos componentes curriculares, no papel de seus docentes, que passa pelo entendimento de que todos os conteúdos devem contar com imersões (teóricopráticas) no dia a dia da escola, além de intervenções interdisciplinares. Em outras palavras, a responsabilidade coletiva pela formação inicial é indispensável para atender, de fato, às orientações e normas que tratam das licenciaturas. Uma vez assumida tal responsabilidade, diferentes estratégias para viabilizar contatos e vivências com e na escola serão planejadas e desenvolvidas ao longo de todo o curso, já que neste caso há real legitimidade da ação.

Outro aspecto de grande relevância reconhecido pelos docentes supervisores e coordenadores de turma com a realização do estágio curricular supervisionado foi a possibilidade de troca de experiências e formação continuada. Segundo o DS5: "É uma troca mesmo, eles trazem coisas novas para a nossa atuação". Na mesma linha de raciocínio, o DS11 afirmou: "Trazem muita novidade. Por exemplo, uma atividade que você já fez tantas vezes, eles vêm e trazem uma coisa completamente diferente ou atualizada, eu falo: 'Como é que eu não pensei nisso?". O DS3 afirmou que "é importante para eles (estagiários) e para nós também, porque os meus estagiários trouxeram atividades que eu nunca tinha visto e que 
foi muito bom para mim. Eles podem aprender comigo, mas eu aprendi com eles também". O DS5 ressaltou que "é uma forma de atualização e troca de experiências". Os demais professores participantes do grupo focal indicaram o estágio como possibilidade de conhecer outras atividades, jogos, brincadeiras, variações, músicas, histórias e formas de ensinar, de forma a contribuir para a sua reflexão, avaliação e qualificação profissional.

O estágio curricular supervisionado como possibilidade de atualização e formação continuada é uma das formas de enfatizar sua importância e significância no contexto escolar, pois se apropriando da concepção de configuração interdependente na associação entre universidade e escola, o estágio tem valor não apenas quando visto e considerado de forma unilateral e fragmentada, como normalmente acontece, mas também nas possibilidades de troca, compartilhamento e coparticipação entre as instituições educacionais (Pimenta e Lima, 2012; Aroeira, 2014; Batista, 2014; Iza e Souza Neto, 2015).

No contexto da Educação Física, essa possibilidade de troca de experiências e formação continuada parece ser mais representativa, tendo em vista as múltiplas formas de vivências, manifestações e explanações dos temas e conteúdos dessa disciplina. Assim, o estágio curricular supervisionado na formação de docentes de Educação Física se configura num "caminho de mão dupla" para "alimentar" as práticas pedagógicas dos estudantes e dos docentes atuantes (Silva Júnior, 2016).

No entanto, Borges (2005) e Benites et al. (2012) afirmam que uma das dificuldades do estágio curricular supervisionado é o fato de os docentes supervisores não se reconhecerem como integrantes do processo de formação ou mesmo confortáveis nessa dinâmica, já que não foram formados para ensinar docentes, mas sim, alunos, situação encontrada não só no Brasil, mas em outros países, como no estudo de Dunning et al. (2011), que retrata as dificuldades do docente da escola no sentimento de pertencimento da formação do futuro docente de Educação Física na Irlanda. Ainda, de acordo com Souza Neto, Sarti e Benites (2016), é prevalente na escola o acolhimento dos estagiários como alunos da universidade e não como (potenciais) futuros docentes, além de que, por outro lado, os estagiários não reconhecem a instituição como um ambiente de formação profissional.

Nesse sentido, Sampaio (2014) reforça a necessidade de reconhecer o papel do docente supervisor no processo formativo dos acadêmicos, mas alerta que é preciso levar em consideração as inúmeras funções e atribuições crescentes que esses docentes têm e exercem no cotidiano das escolas, sendo que, muitas vezes, não conseguem atender às necessidades de apoio aos seus próprios alunos. De qualquer forma, as ações dos docentes 
colaboradores e a própria escola são integrantes da formação dos futuros docentes, pois cabe aos mesmos a interação pedagógica e o oferecimento de suporte aos sujeitos envolvidos.

Nesse contexto, reconhece-se a importância e necessidade da articulação de todos sujeitos envolvidos com o estágio curricular supervisionado na formação dos futuros docentes de Educação Física, como forma de agregar saberes e possibilidades no fortalecimento de ações que promovam a qualidade do ensino.

\section{Conclusões}

Os resultados da pesquisa apresentam alguns desdobramentos do estágio curricular supervisionado na formação inicial de docentes de Educação Física na realidade de uma universidade pública no sul do Brasil, a partir da perspectiva dos agentes envolvidos (estagiários, docentes supervisores e docentes coordenadores de turma). As discussões apresentadas podem indicar que os atores envolvidos com o estágio curricular supervisionado no curso de Educação Física em questão, reconhecem esta etapa como indispensável para a formação docente, por isso enfatizam a necessidade de fortalecer esse componente.

Os resultados também permitem afirmar que as ações do estágio curricular supervisionado favorecem o conhecimento da realidade ao permitirem trocas entre universidade e escola, estagiários e supervisores. Ao conhecer a realidade escolar, 0 estudante se depara com questões administrativas, pedagógicas e de infraestrutura, e passa a refletir sobre as possibilidades de trabalho e ações desenvolvidas pelo docente supervisor, articulando-as aos conhecimentos aprendidos na universidade e debatidos com os docentes coordenadores de turma de estágio.

Ao compreender teorias e práticas e dar sentido e ressignificado às mesmas por meio da proposta de soluções e ações, o estágio curricular supervisionado acaba por favorecer a constituição da identidade docente ao intensificar trocas de experiências, a consolidação de aprendizagens, reflexões sobre a formação inicial e a intervenção docente. O que se constata nos achados da presente pesquisa é que essa aproximação com o campo escolar ainda tem se centrado nas ações do estágio, por isso exige reformulações no curso.

Ressalta-se que alterações curriculares são desafiadoras e demandam predisposição para a releitura do programa de formação, com o intuito de aproximar, cada vez mais, os futuros docentes e o ambiente interventivo. Assim, talvez seja possível vislumbrar avanços no processo de formação inicial em Educação Física que oportunizem posturas docentes condizentes com os desafios profissionais da educação básica. 
Ressalta-se que a contribuição desta pesquisa passa pelo compartilhamento das representações sobre o estágio curricular supervisionado nas vozes daqueles diretamente envolvidos com esse processo, os quais relatam quadros que auxiliam na identificação do que ainda precisa de maior atenção na formação docente em Educação Física. Em especial, temse que o "espaço de fala" foi coletivo, ou seja, não houve foco exclusivo nas impressões dos docentes universitários, todos os envolvidos tiveram voz para apresentar suas impressões e enriquecer os debates. Este aspecto permitiu apresentar um cenário ampliado para alcançar todos os agentes sociais que impactam e são impactos por esta etapa da formação inicial, diferentemente de expor olhares fragmentados sobre um fenômeno.

Foi possível apresentar importantes indicadores (desdobramentos e possibilidades) para o fortalecimento dessa prática pedagógica, entre os quais se destacam: a) o estágio como o peça fundamental na formação identitária do futuro docente de Educação Física, tendo em vista a possibilidade de interação real com o campo de atuação; b) a escola como um campo de vivência que possibilita experimentações do que se aprende na universidade e de questionamento para a formação recebida; c) a necessidade de olhar para o estágio como fundamental para a formação docente, mas não como única aproximação dos futuros docentes com a escola; d) o entendimento de que os cursos de formação (seus docentes) precisam reconhecer a reciprocidade que existe entre escola e universidade, de forma a fortalecer essa "mão de via dupla" entre ambas as instituições de ensino.

Mesmo com o atendimento do objetivo proposto, é possível identificar a limitação do espaço social. Contudo, esperamos contribuir para que as análises aqui desenvolvidas provoquem reflexões em outras realidades que, por sua vez, estimulem mudanças curriculares a fim de aproximá-los das escolas, já que estas também se configuram como espaços sociais de formação docente. Ademais, há a expectativa de que o próprio estágio curricular seja “olhado" por docentes constantemente e de forma coletiva, não só pelos próprios responsáveis diretos por este componente curricular.

Outras pesquisas podem ampliar o cenário do fenômeno aqui investigado, por meio do mapeamento de outras instituições de ensino superior (públicas e privadas) questionando como compreendem a articulação entre os conhecimentos ensinados nos diversos componentes curriculares e as demandas da rotina escolar. Isso passa não só pela análise documental do projeto do curso e da matriz curricular, especificamente, mas também (e talvez mais importante) pelas representações docentes em relação às suas responsabilidades diante 
da formação inicial de docentes de Educação Física, o que extrapola enormemente cada uma das disciplinas.

Também, ainda pouco aparecem nas pesquisas educacionais as condições objetivas para efetivar todas as normativas (e suas mudanças frequentes) relacionadas à formação de docentes, sendo que isso passa pelas próprias comissões que compõem o Ministério da Educação, por exemplo, e as decisões destes agentes públicos que dia a dia definem o andamento das ações, tanto na Educação Básica quanto no Ensino Superior. Portanto, há ainda a necessidade de averiguar as condições objetivas para avançar na formação inicial docente conforme o que é exigido pelas resoluções e leis pertinentes, haja vista os retrocessos ocasionados por escolhas governamentais que não priorizam a educação, reduzem as verbas da área e, no mínimo, inviabilizam diversas ações que poderiam provocar uma formação cada vez mais humana, crítica, diversa e qualificada.

\section{Agradecimentos}

Agradecimentos à Fundação Araucária de Apoio ao Desenvolvimento Científico e Tecnológico do Estado do Paraná e à Coordenação de Aperfeiçoamento de Pessoal de Nível Superior (CAPES) pelo apoio a esta pesquisa.

\section{Referências}

Aroeira, Kalline Pereira. (2014). Estágio Supervisionado e possibilidades para uma formação com vínculos colaborativos entre a universidade e a escola. En M.I Almeida y S. Pimenta Garrido (Eds.), Estágio Supervisionado na formação docente: educação básica e educação de jovens e adultos (pp. 113-151). São Paulo, Brasil: Cortez.

Ball, Stephen John. (1989). La micropolítica de la escuela: hacia una teoría de la organización escolar. Barcelona, España: Paidós.

Bardin, Laurence. (2013). Análise de conteúdo. São Paulo: Edições 70.

Batista, Paula. (2014). O papel do estágio profissional na (re)construção da identidade profissional no contexto da Educação Física: cartografia de um projeto de investigação. En P. Batista, A. Graça y P. Queirós (Eds.), O estágio profissional da (re) construção da identidade profissional em educação física (pp. 9-42). Porto, Portugal: Ed. U. Porto.

Belton, Sarah Jane., Woods, Catherine., Dunning, Carol., y Meegan, Sarah. (2010). The evaluation of a cooperating physical education teachers programme (COPET). European Physical Education Review, 16(2), 141-154. Recuperado de https://journals.sagepub.com/doi/10.1177/1356336X10381302 
Benites, Larissa., Almeida, Sérgio Roberto., Custódio, Nicole., Souza, Sabrina de., Maciel, Larissa Fernanda., y Poulsen, Fernanda. (2019). O processo de reflexão sobre a própria prática de futuros professores de Educação Física. Educação: Teoria e Prática, 29(60), 98-120. doi: http://dx.doi.org/10.18675/1981-8106

Benites, Larissa., Cyrino, Marina., y Souza Neto, Samuel de. (2013). Estágio curricular supervisionado: a formação do professor-colaborador. Olh@res, 1(1), 116-140. Recuperado de https://periodicos.unifesp.br/index.php/olhares/article/view/32/5

Benites, Larissa Cerignoni., Souza Neto, Samuel., Borges, Cecília., y Cyrino, Marina. (2012). Qual o papel do professor colaborador no contexto do estágio curricular supervisionado na educação física?. Revista Brasileira de Ciência e Movimento, 20(4), 13-25. Recuperado de https://portalrevistas.ucb.br/index.php/RBCM/article/view/3286/2282

Benites, Larissa., Vieira do Nascimento, Juarez., Milistetd, Michel., y Farias, Gelcemar. (2016). Análise de conteúdo na investigação pedagógica em educação física: estudo sobre estágio curricular supervisionado. Movimento: Revista de Educação Física da UFRGS, 22(1), 35-50. Recuperado de https://seer.ufrgs.br/Movimento/article/view/53390/36516

Bertini Junior, Nestor., y Tassoni, Elvira Cristina Martins. (2013). A Educação Física, o docente e a escola: concepções e práticas pedagógicas. Revista Brasileira de Educação Física e Esporte, 27(3), 467-83. $\quad$ Recuperado de https://www.scielo.br/pdf/rbefe/v27n3/v27n3a13.pdf

Bisconsini, Camila Rinaldi. (2013). Formação inicial para docência: relações entre estágio supervisionado, Universidade e Escola (Dissertação de mestrado). Universidade Estadual de Maringá, Brasil. Recuperado de http://repositorio.uem.br:8080/jspui/bitstream/1/5723/1/Camila\%20Rinaldi\%20Bisconsin i 2013.pdf

Bisconsini, Camila Rinaldi., Flores, Patric Paludett., y Oliveira, Amauri Aparecido. (2016). Formação inicial para a docência: o estágio curricular supervisionado na visão de seus coordenadores. Journal of Physical Education, 27(1), e2702. doi: https://doi.org/10.4025/iphyseduc.v27i1.2702

Bisconsini, Camila Rinaldi., y Oliveira, Amauri Aparecido Bássoli de. (2018). A Prática como Componente Curricular na formação inicial de professores de Educação Física. Movimento: Revista de Educação Física da UFRGS, 24(2), 455-470. Recuperado de https://seer.ufrgs.br/Movimento/article/view/76705/48570

Bisconsini, Camila Rinaldi., Teixeira, Fabiane Castilho., Anversa, Ana Luíza Barbosa., y Oliveira, Amauri Aparecido Bássoli de. (2019). O estágio curricular supervisionado das licenciaturas na perspectiva de professores supervisores. Corpoconsciência, 23(1), 75$87 . \quad$ Recuperado de https://periodicoscientificos.ufmt.br/ojs/index.php/corpoconsciencia/article/view/7497

Bogdan, Robert., y Biklen, Sari. (2013). Investigação qualitativa em educação: uma introdução à teoria e aos métodos. Porto, Portugal: Porto Editora. 
Borba, Jônatas Costa Brasil., y Wittizorecki, Elisandro Schultz. (2013). Micropolítica escolar e o trabalho docente em educação física: negociações, acordos e concessões. Revista Didática Sistêmica, 55-68. Recuperado de https://periodicos.furg.br/redsis/article/view/4169/2715

Borges, Cecilia. (2005). A formação de docentes de Educação Física e seus saberes profissionais. En C. Borges y J.F. Desbiens (Eds.), Saber, formar e intervir para uma Educação Física em mudança (pp. 157-190). Campinas, Brasil: Autores Associados.

Brasil. (2019). Resolução no 2, de 20 de dezembro de 2019. Brasília-DF, Brasil: Ministério da Educação. Recuperado de http://portal.mec.gov.br/docman/dezembro-2019pdf/135951-rcp002-19/file

Chepyator-Thomson, Jepkorir Rose., y Liu, Wenhao. (2003). Pre-service teachers' reflections on student teaching experiences: Lessons learned and suggestions for reform in PETE programs. The Physical Educator, 60(2). Recuperado de https://js.sagamorepub.com/pe/article/view/3839

Cristovão, Silvio Cesar., y Ayoub, Eliana. (2019). Estágio supervisionado: aprendizados de estagiários da Educação Física. Revista Triângulo, 12(2), 89-100. Recuperado de http://seer.uftm.edu.br/revistaeletronica/index.php/revistatriangulo/article/view/3512/356 1

Cyrino, Marina. (2016). Do acolhimento compartilhado: a construção colaborativa de uma proposta para o estágio curricular no curso de pedagogia (Tese de doutorado). Universidade Estadual Paulista "Júlio de Mesquita Filho", Brasil. Recuperado de https://repositorio.unesp.br/bitstream/handle/11449/137997/cyrino m dr rcla.pdf?sequ ence $=3$ \&isAllowed $=y$

Duarte, Rosália. (2004). Entrevistas em pesquisas qualitativas. Educar, 24(1), 213-225. Recuperado de https://www.scielo.br/pdf/er/n24/n24a11.pdf

Dubar, Claude. (1999). A sociologia do trabalho frente à qualificação e à competência. Educação \& Sociedade, 19(64), 87-103. doi: https://doi.org/10.1590/S0101$\underline{73301998000300004}$

Dunning, Carol., Meegan, Sarah., Woods, Catherine., and Belton, Sarah Jane. (2011). The impact of the COPET programme on student PE teachers' teaching practice experiences. European Physical Education Review, 17(2), 153-165. doi: https://doi.org/10.1177\%2F1356336X11413182

Farias, Gelcemar Oliveira., Folle, Alexandra., Both, Jorge., Saad, Michél Angillo., Teixeira, Anderson Santiago., Salles, William das Neves., y Nascimento, Juarez Vieira. (2008). Preocupações pedagógicas de estudantes-estagiários na formação inicial em educação física. Motriz: Journal of Physical Education, 14(3), 310-319. doi: https://doi.org/10.5016/2124 
Flores, Maria Assunção. (2015). Formação docente e identidade profissional: tensões e (des)continuidades. Educação, 38(1), 138-146. doi: http://dx.doi.org/10.15448/19812582.2015.1.15973

Flores, Patric., Caraçato, Yedda Maria da Silva., Anversa, Ana Luiza., Solera, Bruna., Costa, Luciane Cristina Arantes da., Oliveira, Amauri Aparecido Bássoli de., y Souza, Vânia de Fatima Matias de. (2019). Formação inicial de professores de educação física: um olhar para o estágio curricular supervisionado. Caderno de Educação Física e Esporte, 17(1), 61-68. doi: http://dx.doi.org/10.36453/2318-5104.2019.v17.n1.p61

Gomes, Patrícia Maria Silva., Ferreira, Cátia Patrícia Pereira., Pereira, Ana Luísa., y Batista, Paula Maria Fazendeiro. (2013). A identidade profissional do professor: um estudo de revisão sistemática. Revista Brasileira de Educação Física e Esporte, 27(2), 247-267. Recuperado de https://www.scielo.br/pdf/rbefe/v27n2/a09v27n2.pdf

Gatti, Bernadete Angelina. (2012). Grupo focal na pesquisa em ciências sociais e humanas. Brasília, Brasil: Liber Livro.

Hill, Grant., y Brodin, Kristie. (2004). Physical education teachers' perceptions of the adequacy of university course work in preparation for teaching. The Physical Educator, 61(2), 7587. Recuperado de https://js.sagamorepub.com/pe/article/view/2584

Iza, Dijnane Fernanda Vedovatto, y Souza Neto, Samuel. (2015). Os desafios do estágio curricular supervisionado em educação física na parceria entre universidade e escola. Movimento: Revista da Escola de Educacao Física da UFRGS, 21(1), 111-124. Recuperado de https://seer.ufrgs.br/Movimento/article/view/46271/33336

Jones, Marion., y Straker, Katherine. (2006). What informs mentors' practice when working with trainees and newly qualified teachers? An investigation into mentors' professional knowledge base. Journal of education for teaching, 32(2), 165-184. doi: https://doi.org/10.1080/02607470600655227

Kravchychyn, Claudio., Cardoso, Sônia Maria Vicente., Moretti, Lúcia., Helena Tiosso., y Oliveira, Amauri Aparecido Bássoli de. (2011). Educação física escolar brasileira: caminhos percorridos e "novas/velhas" perspectivas. Revista Teoria e Prática da Educação, 14(1), 107-118. Recuperado de http://periodicos.uem.br/ojs/index.php/TeorPratEduc/article/view/16109/8717

Krug, Hugo Norberto., Krug, Rodrigo de Rosso., Marques, Marta Nascimento., y Conceição, Victor Julierme Santos da Conceição. (2015). Ser professor na escola: de aluno a professor no estágio curricular supervisionado na licenciatura em Educação Física. Revista Linhas, 16(30), 248-269. doi: http://dx.doi.org/10.5965/1984723816302015248

Krug, Rodrigo de Rosso., y Krug, Hugo Norberto. (2010). O estágio curricular supervisionado na percepção dos acadêmicos da licenciatura em educação física do CEFD/UFSM: Que momento é este?. Arquivos em Movimento: revista eletrônica da Escola de Educação Física e Desportos, 6(2), 101-116. Recuperado de https://revistas.ufri.br/index.php/am/article/view/9171/7301 
Maffei, Willer Soares. (2014). Prática como Componente Curricular e estágio supervisionado na formação de professores de Educação Física. Motrivivência, 26(43), 229-244. doi: http://dx.doi.org/10.5007/2175-8042.2014v26n43p229

Martiny, Luis., y Gomes-da-Silva, Pierre. (2014). A transposição didática na educação física escolar: a reflexão na prática pedagógica dos professores em formação inicial no estágio supervisionado. Revista da Educação Física/UEM, 25(1), 81-94. doi: https://doi.org/10.4025/reveducfis.v25i1.20885

Moletta, Andréia Fernanda., Teixeira, Fabiano Augusto., Folle, Alexandra., Nascimento, Juarez Vieira do., Farias, Gelcemar de Oliveira., y Marinho, Alcyane. (2013). Momentos marcantes do estágio curricular supervisionado na formação de professores de educação física. Pensar a Prática, 16(3), 715-730. doi: https://doi.org/10.5216/rpp.v16i3.18705

Neira, Marcos., y Ehrenberg, Mônica. (2013). Análise da proposta de estágio na licenciatura em Educação Física da Universidade de São Paulo. Olh@res, 1(1), 325-348. Recuperado de https://periodicos.unifesp.br/index.php/olhares/article/view/68/13

Negrine, Airton. (2004). Instrumentos de coleta de informações na pesquisa qualitativa. En $V$. Molina Neto y A.N. Triviños (Eds.), A pesquisa qualitativa na Educação Física: alternativas metodológicas (pp. 61-94). Porto Alegre, Brasil: Ed. Universidade/UFRGS/Sulina.

Nóvoa, António. (2009). Para una formación de profesores construida dentro de la profesión. Revista de Educación, 350(1), 203-218. Recuperado de http://www.revistaeducacion.educacion.es/re350/re350 09.pdf

Oliveira, Amauri Aparecido Bássoli de., Silva Júnior, Arestides Pereira da., Bisconsini, Camila Rinaldi., y Flores, Patric Paludett. (2017). O estágio curricular supervisionado na formação permanente do professor de Educação Física. En J. Pontes y J. Airton de Freitas (Eds.), Conhecimentos do professor de Educação Física escolar (pp. 64-94). Fortaleza, Brasil: Eduece.

Pimenta, Selma Garrido., y Lima, Maria Socorro Lucena. (2012). Estágio e docência (7ª ed.). São Paulo, Brasil: Cortez.

Queirós, Paula. (2015). O estágio profissional enquanto espaço de formação profissional. En P. Batista, P. Queirós y R. Rolim (Eds.), Olhares sobre o estágio profissional em Educação Física (pp. 33-51). Porto, Portugal: Ed. U. Porto.

Queirós, Paula., y Graça, Amandio. (2013). A análise de conteúdo (enquanto técnica de tratamento de informação) no âmbito da investigação qualitativa. En I. Mesquita y A. Graça (Eds.), Investigação qualitativa em desporto (vol. 2) (pp. 115-149). Porto, Portugal: Ed. U. Porto.

Salas, Flora Eugenia. (2018). Formación profesional en el campo de la Educación en el contexto actual: Aristas y puntos ciegos. Revista Electrónica Actualidades Investigativas en Educación, 19(2), 1-25. doi: https://doi.org/10.15517/aie.v19i2.37024 
Sampaio, Adelar Aparecido. (2014). Vivências de docentes e de seus licenciandos no final de formação e passagem para o mundo do trabalho: mal/bem-estar docente/discente, autoimagem e autoestima (Tese de doutorado). Pontifícia Universidade Católica do Rio Grande Do Sul, Brasil. $\quad$ Recuperado de http://tede2.pucrs.br/tede2/bitstream/tede/3815/1/460738.pdf

Sampaio, Adelar Aparecido., Stobaus, Claus Dieter., Baez, Marcio Alessandro., y Ahlert, Alvori. (2017). Perspectivas de realização e desenvolvimento profissional em licenciandos. Pensar a Prática, 20(3), 476-487. doi: https://doi.org/10.5216/rpp.v20i3.42193

Santos, Rafaela Gomes dos., Souza, Adriano Lopes., y Barbosa, Franck Nei Monteiro. (2013). Estágio Supervisionado I: o desafio da avaliação nas aulas de educação física escolar. Pensar a Prática, 16(2), 501-518. doi: https://doi.org/10.5216/rpp.v16i2.17384

Silva, Ana Maria Costa e. (2003). Formação, percursos e identidades. Coimbra, Portugal: Quarteto.

Silva Júnior, Arestides Pereira da. (2016). Configurações e relações estabelecidas no estágio curricular supervisionado na formação inicial de professores de educação física (Tese de doutorado). Universidade Estadual de Maringá, Brasil. Recuperado de http://repositorio.uem.br:8080/jspui/bitstream/1/2151/1/000225220.pdf

Silva Júnior, Arestides Pereira., Bisconsini, Camila Rinaldi., Flores, Patric Paludett., Anversa, Ana Luíza Barbosa., y Oliveira, Amauri Aparecido Bássoli de. (2019). As implicações da configuração interdependente entre estagiários e professores supervisores no estágio curricular supervisionado em Educação Física. Motrivivência: Revista de Educação Física, Esporte e Lazer, 31(60), 01-24. doi: https://doi.org/10.5007/2175$\underline{8042.2019 \mathrm{e} 59612}$

Silva Júnior, Arestides Pereira da., Flores, Patric Paludett., Bisconsini, Camila Rinaldi., Anversa, Ana Luíza Barbosa., y Oliveira, Amauri Aparecido Bássoli de. (2016). Estágio curricular supervisionado na formação de professores em educação física: uma análise da legislação a partir da resolução CFE 03/1987. Pensar a Prática, 19(1), 1-1. doi: https://doi.org/10.5216/rpp.v19i1.34854

Silva Júnior, Arestides Pereira da., y Oliveira, Amauri Aparecido Bássoli de. (2018a). Estágio curricular supervisionado na formação de professores de educação física no Brasil: uma revisão sistemática. Movimento: Revista de Educação Física da UFRGS, 24(1), 77-92. doi: http://dx.doi.org/10.22456/1982-8918.67071

Silva Júnior, Arestides Pereira da., y Oliveira, Amauri Aparecido Bássoli de. (2018b). Estágio curricular supervisionado em Educação Física: aproximações com a teoria de Norbert Elias. Revista Electrónica Actualidades Investigativas en Educación, 18(3), 1-20. doi: https://doi.org/10.15517/aie.v18i3.34433

Silva, Sheila Aparecida., Souza, César Augusto., y Checa, Felipe. (2010). Situação do estágio supervisionado em IES privadas da grande São Paulo. Motriz: Journal of Physical Education, 16(3), 682-688. doi: https://doi.org/10.5016/1980-6574.2010v16n3p682 
Silva, Teresa., Batista, Paula., y Graça, Amândio. (2016). A função de supervisão como fator de aprendizagem profissional contínua do professor cooperante de educação física. Revista Internacional de Formação de Professores, 1(3), 10-44. Recuperado de https://periodicos.itp.ifsp.edu.br/index.php/RIFP/article/view/436/331

Souza Neto, Samuel., Benites, Larissa Cerignoni., laochite, Roberto Tadeu., y Borges, Cecilia. (2012). O estágio supervisionado como prática profissional, área de conhecimento e locus de construção da identidade do professor de Educação Física. En J. Nascimento y G.O. Farias (Eds.), Construção da identidade profissional em Educação Física: da formação a intervenção (pp. 113-140). Florianópolis, Brasil: Ed. da UDESC.

Souza Neto, Samuel., Sarti, Flávia Medeiros., y Benites, Larissa Cerignoni. (2016). Entre o ofício de aluno e o habitus de professor: os desafios do estágio supervisionado no processo de iniciação à docência. Movimento: Revista de Educação Física da UFRGS, 22(1), 311-324. Recuperado de https://seer.ufrgs.br/Movimento/article/view/49700/36619

Tang, Sylvia Yee Fan. (2004). The dynamics of school-based learning in initial teacher education. Research Papers in Education, 19(2), 185-204. doi: https://doi.org/10.1080/02671520410001695425

Zabalza, Miguel Angel. (2014). O estágio e as práticas em contextos profissionais na formação universitária. São Paulo, Brasil: Cortez.

Zotovici, Sandra Aparecida., Melo, Janaína Benasse., Campos, Márcia Zendron de., y Lara, Larissa Michelle. (2013). Reflexões sobre o estágio supervisionado no curso de licenciatura em Educação Física: entre a teoria e a prática. Pensar a Prática, 16(2), 568582. doi: https://doi.org/10.5216/rpp.v16i2.16593 
Revista indizada en

scip/o

redalyc latindex

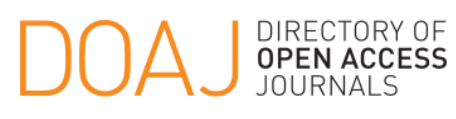

Distribuida en las bases de datos:

๑ Dialnet

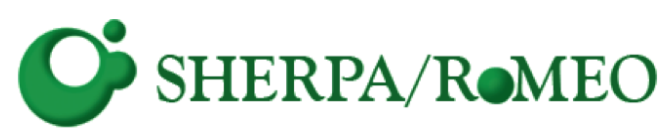

REDIB

Red Iberoamericana

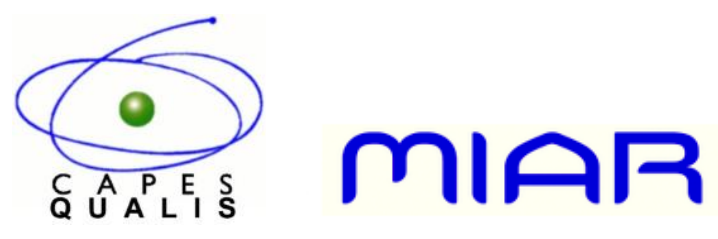

